\title{
Nanoscale
}

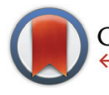

CrossMark

$\leftarrow$ click for updates

Cite this: Nanoscale, 2016, 8, 7384

Received 21st December 2015,

Accepted 8th March 2016

DOI: $10.1039 / c 5 n r 09095 d$

www.rsc.org/nanoscale

\section{Ultrafast triggered transient energy storage by atomic layer deposition into porous silicon for integrated transient electronics $\uparrow$}

\author{
Anna Douglas, t $^{\mathrm{a}}$ Nitin Muralidharan, t $^{\mathrm{a}}$ Rachel Carter, ${ }^{\mathrm{b}}$ Keith Share ${ }^{\mathrm{a}}$ and \\ Cary L. Pint*a,b,c
}

\begin{abstract}
Here we demonstrate the first on-chip silicon-integrated rechargeable transient power source based on atomic layer deposition (ALD) coating of vanadium oxide $\left(\mathrm{VO}_{x}\right)$ into porous silicon. A stable specific capacitance above $20 \mathrm{~F} \mathrm{~g}^{-1}$ is achieved until the device is triggered with alkaline solutions. Due to the rational design of the active $\mathrm{VO}_{x}$ coating enabled by ALD, transience occurs through a rapid disabling step that occurs within seconds, followed by full dissolution of all active materials within 30 minutes of the initial trigger. This work demonstrates how engineered materials for energy storage can provide a basis for next-generation transient systems and highlights porous silicon as a versatile scaffold to integrate transient energy storage into transient electronics.
\end{abstract}

\section{Introduction}

Transient electronics represents a class of devices where a trigger can be used to dissolve or destroy a device and any information it contains. The premise of a transient system is to exhibit stable and invariant device performance until an external trigger is applied, which can be in the form of $\mathrm{pH}$, light, temperature, or a combination of these stimuli. ${ }^{1,2}$ The trigger initiates a series of reactions or mechanisms in the device that partially or fully dissolves the device, and renders

\footnotetext{
${ }^{a}$ Interdisciplinary Materials Science Program, Vanderbilt University, Nashville, TN 37235, USA.E-mail: cary.l.pint@vanderbilt.edu

${ }^{b}$ Department of Mechanical Engineering, Vanderbilt University, Nashville, TN 37235, USA

${ }^{c}$ Vanderbilt Institute of Nanoscale Science and Engineering, Nashville, TN 37235, USA

$\dagger$ Electronic supplementary information (ESI) available: (i) Experimental details for ALD and material fabrication, ellipsometry film thickness, preparation of gel electrolyte and separator, details for electrochemical measurements, HRTEM image of $\mathrm{VO}_{x}$ coated porous silicon, Raman spectroscopy for $\mathrm{VO}_{x}$ as-deposited as well as annealed in air for 1 hour at $450{ }^{\circ} \mathrm{C}$, SEM and transient behavior dissolution tests of uniformly coated $\mathrm{VO}_{x}$ on porous silicon, dissolution tests for $0.1 \mathrm{M}$ and $0.01 \mathrm{M} \mathrm{NaOH}$ trigger solutions, EIS analysis for $\mathrm{VO}_{x}$ coated devices, and EDS compositional analysis of $\mathrm{VO}_{x}$. (ii) Video showing transient behavior of integrated $\mathrm{VO}_{x}$ /porous silicon scaffolds. See DOI: 10.1039/c5nr09095d $\$$ Equal contribution first author.
}

the device inoperable in a manner that destroys the device and any information it may contain. There are many applications that can benefit from transient devices, ranging from information-sensitive electronic devices to biodegradable medical applications. Such a vast array of application areas also brings the requirement of diverse transient properties, including time of dissolution, controlled toxicity, and the type of external trigger source. For example, biological or medical applications may be more centered on toxicity of dissolution products, whereas surveillance and spy applications require fast disablement and dissolution times.

Recent efforts in the development of transient technology have been concentrated in small electronics ${ }^{3-5}$ usually centered on silicon materials, silicon based photovoltaics, ${ }^{1}$ medical energy harvesters, ${ }^{6}$ bioresorbable electronics, ${ }^{7,8}$ and biodegradable primary batteries. ${ }^{9}$ The first rechargeable power source with transient behavior has been described by $\mathrm{Fu}$ et al. which demonstrates a rechargeable lithium ion battery that dissolves through a chemical cascade reaction. ${ }^{10}$ This elegant design involves a power source packaged separately from other electronics or systems that it powers. Building from this work, the intersection of transient energy storage with integrated silicon-based systems could enable facile design of integrated silicon transient electronics and power systems.

Whereas silicon-based materials have been lauded for energy storage capability, stable performance of silicon both in the context of batteries and electrochemical capacitors most often requires surface passivation, usually with carbon or a passive oxide material. ${ }^{11-15}$ This presents a challenge for transient behavior since the robust electrochemical stability of carbon leaves it incompatible with triggers used for transience, and incomplete passivation of the surface (that would enable transience) has the adverse effect of compromised function of the device prior to being triggered. ${ }^{15,16}$ However, one material that has been recently investigated for use in batteries and electrochemical (redox) supercapacitors is vanadium oxide, which is active toward lithium ion intercalation through surface reactions. ${ }^{17-28}$ of the methods to produce vanadium oxide materials, atomic layer deposition (ALD) boasts advan- 
tages of controllable film thickness and uniform surface morphology. ${ }^{17,18,29-31}$ Vanadium oxide has also been shown to dissolve in basic solutions, thus making it suitable for transient applications. ${ }^{10,32,33}$

Therefore, in this report, we demonstrate the first integrated silicon-based on-chip energy storage system that exhibits transient behavior. This builds from vanadium oxide coated onto the interior of porous silicon that is electrochemically etched into a bulk silicon chip. By controlling the ALD deposition profile in a transient scaffold, ultrafast deactivation of the device occurs when exposed to an alkaline trigger solution, and full dissolution of all components occurs within 30 minutes. This identifies a general route of combining the versatility of ALD with porous silicon transient materials to design integrated silicon transient power storage systems.

\section{Results and discussion}

Schematic representation of the concept of an integrated device as shown in Fig. 1 gives insight into fabrication and the transient behavior of the fabricated device. The active energy storage material $\left(\mathrm{VO}_{x}\right)$ is deposited to play a dual role that both (1) inhibits corrosion-based deactivation of nanoscale silicon in electrochemical environments, and (2) provides active redox storage as an electrochemical capacitor. This architecture is designed so that in a triggering environment, the $\mathrm{VO}_{x}$ will dissolve and expose the unstable porous silicon material to corrosive conditions that dissolve and remove all materials except the bulk silicon. However, in the electrolyte environment, the $\mathrm{VO}_{x}$ /porous silicon system will exhibit stable, invariant performance. Here, porous silicon plays a role of a tunable, high surface area transient template for the coating of active material, and can be integrated directly into bulk silicon materials using standard semiconductor processing technology. This means that this material can be processed into the backside of silicon electronics, or even coupled with other silicon-based transient electronics, which is schematically illustrated in Fig. 1. A gel based PVA/0.5 $\mathrm{M} \mathrm{LiClO}_{4}$ electrolyte (ESI†) was used as an electrolyte to couple $\mathrm{VO}_{x}$ coated porous silicon transient devices. Additionally, for this system to be fully transient, a polyethylene oxide (PEO) based separator (ESI $\dagger$ ), which dissolves in the aqueous trigger media, was used. This leads to a device that can be a functional energy storage material until an external trigger $(1 \mathrm{M} \mathrm{NaOH})$ disables and disintegrates the device.

A key aspect of this transient device design is the ALD deposition of $\mathrm{VO}_{x}$ materials. ${ }^{34,35}$ To accomplish this, we utilized sequential pulses of $\mathrm{VO}\left(\mathrm{OC}_{3} \mathrm{H}_{7}\right)_{3}$ and $\mathrm{H}_{2} \mathrm{O}$ with 2 second residence times. Due to the diffusion-limited growth of ALD coatings on the interior of high aspect ratio nanoporous materials, longer residence times are required for uniform coatings. ${ }^{36}$ However, to design a material with optimized transient performance, we reverted to shorter residence times which yield a thickness gradient from top of the porous material to the bottom. Thickness of the films was measured based on ellipsometry of films coated on planar silicon surfaces (ESI $\dagger$ ) and penetration of the $\mathrm{VO}_{x}$ coatings was confirmed based on scanning electron microscopy (SEM) characterization. Full details of the ALD chemistry and experimental parameters are detailed in the ESI. $\dagger$ Uncoated porous silicon with $5 \mu \mathrm{m}$ deep pores is shown in Fig. 2a. $\mathrm{VO}_{x}$ deposition on the porous silicon for 100 and 400 ALD cycles and the resulting pore morphology is shown in Fig. $2 \mathrm{~b}$ and c, respectively. The total areal mass loading of vanadium oxide in these composites is $0.057 \mathrm{mg}$ $\mathrm{cm}^{-2}$ and $0.229 \mathrm{mg} \mathrm{cm}^{-2}$ for 100 and 400 ALD cycles, respectively. Evidence of a thicker $\mathrm{VO}_{x}$ coating is visually apparent in the case of 400 ALD cycles when compared to 100 ALD cycles,

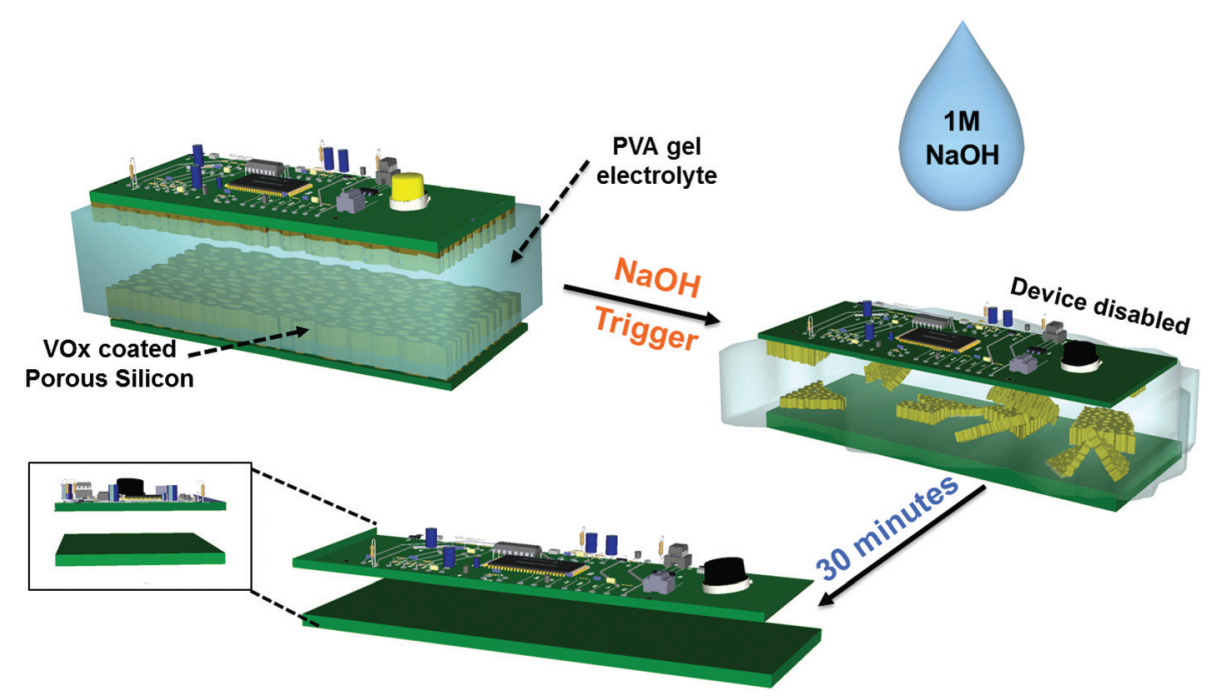

Fig. 1 Schematic representation demonstrating the integration of transient energy storage into silicon-based (transient or non-transient) electronics. Triggering the system with $1 \mathrm{M} \mathrm{NaOH}$ aqueous solution leads to near-immediate disablement of the device, and full dissolution within 30 minutes. 

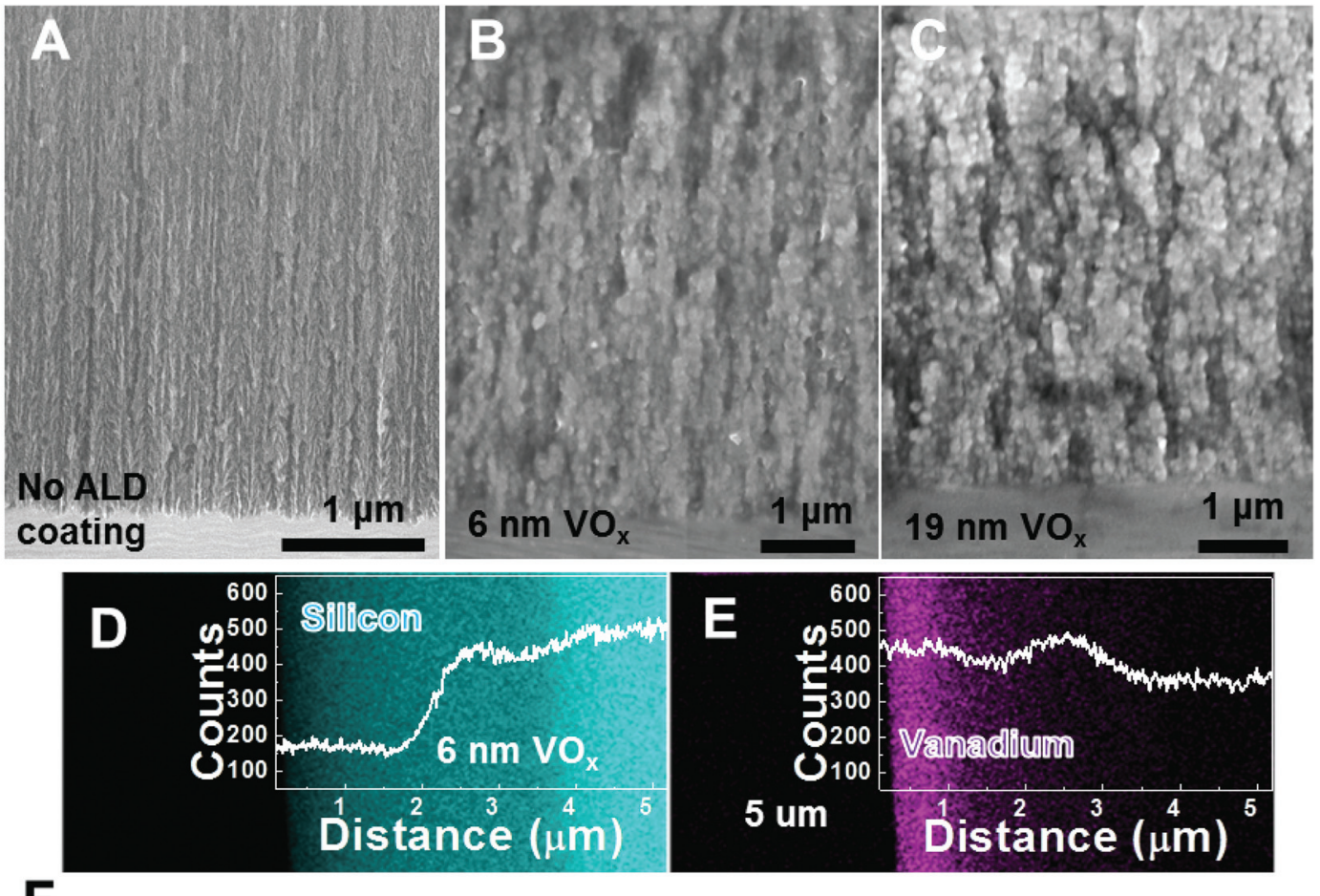

$\mathbf{F}$
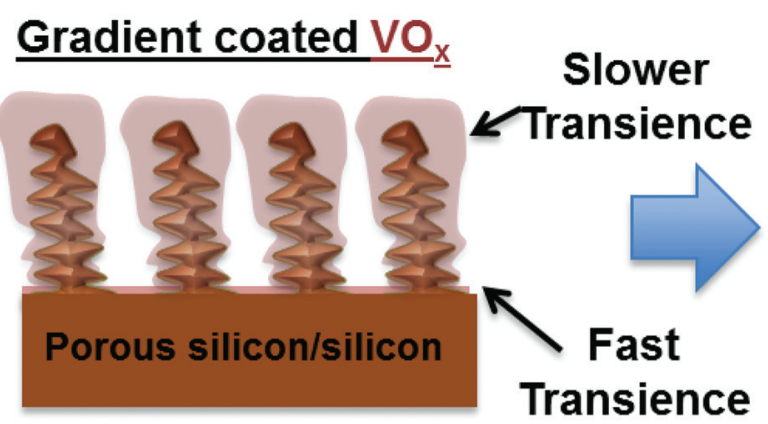

Ultrafast Disabled Device

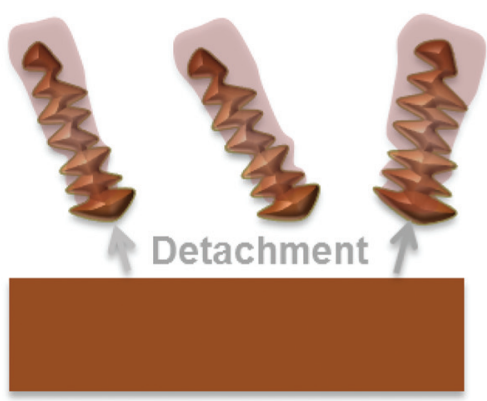

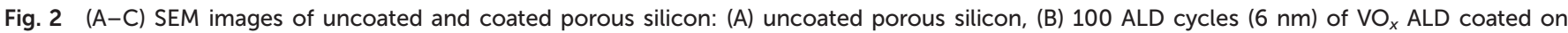
porous silicon, and (C) 400 ALD cycles $\left(19 \mathrm{~nm}\right.$ ) of $\mathrm{VO}_{x}$ ALD coated on porous silicon. (D-E) Cross sectional EDX maps of VO $\mathrm{O}_{x}$ coated porous silicon showing: (D) silicon and (E) vanadium down the cross-section of the porous silicon. (F) Scheme showing how the thinner coating at the porous silicon base leads to ultrafast disablement.

noting that the underlying porous silicon template is identical between Fig. 2a-c. Energy dispersive X-ray (EDS) on the crosssection of the porous silicon was performed, and line profiles corresponding to EDS scans are shown in Fig. 2d and e. Based on EDS analysis, relative weight and atomic percentages of vanadium and oxygen are $64 \%$ vanadium and $36 \%$ oxygen (weight) and $36 \%$ and $64 \%$ (atomic), respectively. To further analyze the state of the $\mathrm{VO}_{x}$ material, we annealed ALD deposited $\mathrm{VO}_{x}$ in air at $450{ }^{\circ} \mathrm{C}$ for 1 hour and characterized the material using Raman spectroscopy (see ESI $\dagger$ ) before and after annealing. Due to the highly Raman active modes of crystalline vanadium oxide, Raman analysis demonstrates the transition from a non-crystalline or amorphous state of vanadium oxide to crystalline $\mathrm{V}_{2} \mathrm{O}_{5} \cdot{ }^{35}$ We therefore associate the ALD material to a non-stoichiometric and non-crystalline form of vanadium oxide which we label as $\mathrm{VO}_{x}$. Notably, a greater concentration of $\mathrm{VO}_{x}$ is observed at the top of the porous silicon material, and this slightly decreases near the base of the porous silicon. Whereas this effect is due to diffusion-limited ALD growth that can be improved with higher vapor pressure precursors, longer residence times, or higher temperatures, such asymmetric thickness profiles bring a distinct benefit to the function of a transient device. In this design, the thin coating of the $\mathrm{VO}_{x}$ active material near the base of the porous silicon will dissolve away more rapidly than the thicker coating near the top of the material, (Fig. 2f) and this will in-turn expose the base of the porous silicon - which is highly reactive in aqueous basic solutions. This causes the rapid detachment of the active material from the base (within seconds), which deactivates the energy storage function of the material. There- 
fore, transience occurs through a two-step process with rapid deactivation on the timescale of a few seconds, and eventual full dissolution on longer scales of minutes. To explicitly demonstrate this mechanism, we produced a control sample where the residence time was increased, leading to a uniform $\mathrm{VO}_{x}$ coating in the porous silicon. This system exhibited no rapid deactivation and a $4 \times$ longer transience time than the gradient coated samples (Fig. S4 and S5 $\uparrow$ ). Notably, this highlights the principle that engineered coating processes can enable wide versatility in the utility of transient functions in energy storage systems.

Electrochemical measurements were carried out to assess the energy storage capability of these transient devices. This device was tested in a symmetric two-electrode configuration to assess the storage capability of the $\mathrm{VO}_{x}$, as three-electrode measurements can over exaggerate the measured results. ${ }^{34,37}$ As the focus of this work is a transient, integrated energy storage platform, further development asymmetric designs can build upon the same general approach and enable a tunable range of operating voltages relative to that measured for $\mathrm{VO}_{x}$. To characterize the electrochemical performance of these devices, we compared the same ALD parameters using 300, 400 , and 500 ALD cycles, which corresponds to $\sim 15,19$, and
$24 \mathrm{~nm}$ thick coatings based on extrapolated from ellipsometry analysis (ESI $\dagger$ ). Cyclic voltammograms (CV) taken at $100 \mathrm{mV} \mathrm{s}^{-1}$ and galvanostatic charge-discharge curves taken at $0.1 \mathrm{~mA} \mathrm{~cm}{ }^{-2}$ corresponding to $\mathrm{VO}_{x}$ coated onto porous silicon templates at these three thicknesses are shown in Fig. 3a and b. Analysis of both CV and charge-discharge curves emphasizes that a $19 \mathrm{~nm}$ thick $\mathrm{VO}_{x}$ layer corresponding to $400 \mathrm{ALD}$ cycles exhibits the most fully developed stable redox peaks centered around $0 \mathrm{~V}$ which is expected for faradaic redox capacitors in symmetric two-electrode configurations. Compared to other thicknesses, this coating thickness also minimizes the resistance polarization in the device that is attributed to power loss on fast charge cycling. This coating thickness also leads to the highest total measured capacitance based on galvanostatic measurements. As the electrolyte used in this system is PVA/ $\mathrm{LiClO}_{4}$, the redox behavior of $\mathrm{VO}_{x}$ arises from the near-surface redox intercalation of $\mathrm{Li}^{+}$represented by:

$$
x \mathrm{Li}^{+}+y \mathrm{VO}_{x}+\mathrm{e}^{-} \leftrightarrow \operatorname{Li} x\left(\mathrm{VO}_{x}\right) y
$$

Two key variables represent the total energy storage capability of these materials: (1) the total mass of $\mathrm{VO}_{x}$ coated onto porous silicon that is optimized with thick coatings, and (2) the ability for the electrolyte to penetrate into the pore struc-
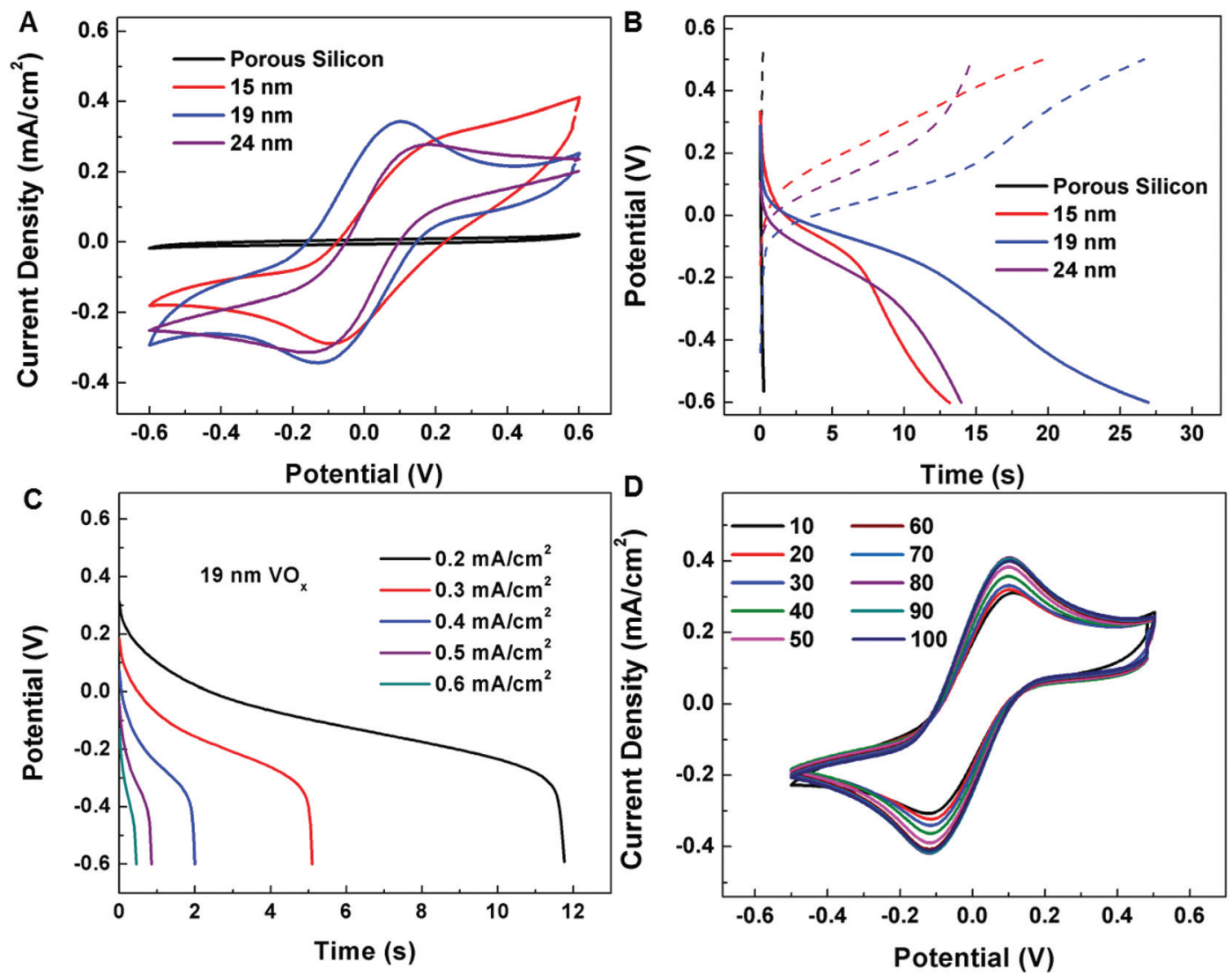

Fig. 3 (A) Cyclic voltammograms $\left(100 \mathrm{mV} \mathrm{s}^{-1}\right)$ of $\mathrm{VO}_{x}$ coated porous silicon at different coating thicknesses compared to uncoated porous silicon reference, (B) galvanostatic charge-discharge curves showing the $5^{\text {th }}$ cycle for each coating thickness, and (C) galvanostatic rate study showing discharge performance as a function of discharge current, and (D) voltammetric cycling performance for transient energy storage device with $19 \mathrm{~nm}$ $\mathrm{VO}_{x}$ coating on porous silicon. 
ture that is inhibited when thick coatings are applied. For the sample with 400 ALD cycles, specific capacitance based on charge-discharge curves is measured as $\sim 21 \mathrm{~F} \mathrm{~g}^{-1}$. Whereas this specific capacitance is lower than that achieved using materials such as $\mathrm{RuO}_{2}$ or $\mathrm{Ni}(\mathrm{OH})_{2}$, the $\mathrm{VO}_{x}$ provides a distinct medium between transient behavior, the surface passivation role for electrochemical use of porous silicon, and a versatile ALD chemistry that can enable the ultrafast transience on silicon templates. These thickness studies hence establish an optimized $\mathrm{VO}_{x}$ thickness for this system near $19 \mathrm{~nm}$, and less than $24 \mathrm{~nm}$. Charge-discharge tests at various current densities were performed on the devices with $19 \mathrm{~nm} \mathrm{VO}_{x}$ coatings. The discharge curves at various current densities (Fig. 3c) indicate stable near-surface redox intercalation reactions represented by the plateau region. Increasing current densities decreases the plateau region corresponding to decreased charge storage which is a result of the nature of these coated 3D porous electrodes. At higher rates, not all redox active $\mathrm{VO}_{x}$ sites on the $3 \mathrm{D}$ porous silicon structure are accessed resulting in decreased charge storage. The $\mathrm{VO}_{x}$ coatings on the porous silicon substrate were optimally chosen to achieve good transience as well as respectable electrochemical performance for integrated applications. Durability measurements were performed on devices prepared with the optimal coating thickness (Fig. 3d) for over $100 \mathrm{CV}$ cycles, showing stable cycling behavior. Based on the electrochemical tests, $19 \mathrm{~nm}$ thick $\mathrm{VO}_{x}$ coated porous silicon was used to demonstrate the transient behavior of the device. Electrochemical Impedance Spectroscopy (EIS) measurements were further performed in a symmetric two electrode setup with $19 \mathrm{~nm} \mathrm{VO}_{x}$ coatings and the results indicate low equivalent series resistance and charge transfer resistance indicating stable charge storage capability (see ESI $\dagger$ ).

Demonstration of the transient behavior of the $\mathrm{VO}_{x}$ based porous silicon system (Fig. 4) highlights the potential application of integrated transient energy storage using this technique. Transient behavior triggered by an alkaline solution $(1 \mathrm{M} \mathrm{NaOH})$ disables the $\mathrm{VO}_{x}$-porous silicon electrode in less than 5 seconds due to the electrode design discussed in Fig. 2. This is in part due to the reactive nature of porous silicon in the triggering solution, with the full (uncoated) porous silicon material dissolution occurring in well under 1 min (Fig. 4a). Coating the porous silicon surface with $\mathrm{VO}_{x}$ enables surface passivation in the electrolyte environment, but rapid dissolution of the full material when exposed to the trigger solution. The $\mathrm{VO}_{x}$ gradient that results in a thinner coating near the bottom of the porous material results in faster dissolution of this bottom section of the material, causing deactivation to occur within 5 seconds due to detachment of this material. Such ultrafast triggering can be highly beneficial for applications requiring immediate transience. A video of this ultrafast deactivation and eventual dissolution is included in the ESI. $\dagger$ Following the dissolution of the porous silicon/bulk silicon interface, the $\mathrm{VO}_{x}$ coated layer was observed to fully dissolve in around 30 minutes. In a full device, the penetration of the trigger solution into the device happens due to the initial swelling of the gel electrolyte. The transient behavior of the $\mathrm{PEO} / \mathrm{LiClO}_{4}$ separator is given in Fig. 4c. The polymer separator dissolves within 30 minutes following the initial swelling in the trigger solution. Whereas a $1 \mathrm{M} \mathrm{NaOH}(\mathrm{pH}=13)$ triggering solution ensures rapid dissolution, certain applications of transient electronics

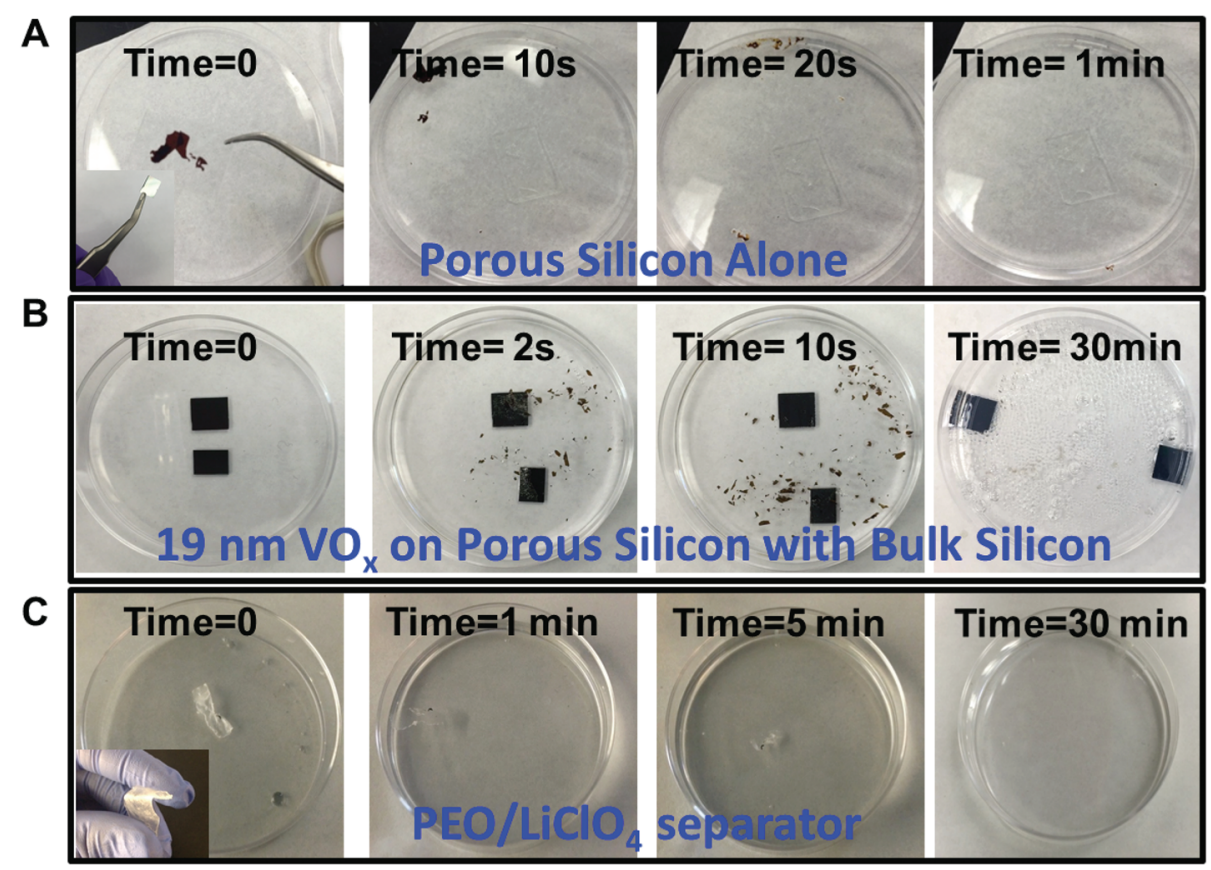

Fig. 4 Transient dissolution of device components including (A) uncoated porous silicon (control), (B) $19 \mathrm{~nm}$ VO $\mathrm{O}_{x}$ gradient coating on porous silicon with bulk silicon substrate (left behind after $30 \mathrm{~min}$ ), and (C) $\mathrm{PEO} / \mathrm{LiClO}_{4}$ separator. Dissolution tests with uniformly coated VO $\mathrm{O}_{x}\left(\mathrm{ESI}+\mathrm{f}_{\text {) }}\right.$ support the mechanism of the gradient coating in rapid deactivation of the energy storage material that is illustrated in these dissolution studies. 
require low toxicity trigger solutions. We have therefore included dissolution tests of $0.1 \mathrm{M}(\mathrm{pH}=11)$ and $0.01 \mathrm{M}$ $(\mathrm{pH}=9) \mathrm{NaOH}$ solutions (see ESI $\dagger$ ), which show similar rapid transient deactivation except with longer time to achieve full dissolution. Such transient systems may also be ideally suited to operate in ambient humid conditions since the transient $\mathrm{VO}_{x} /$ porous silicon electrode itself is stable in such conditions.

Whereas this effort so far demonstrates the transience of $\mathrm{VO}_{x} /$ porous silicon electrodes, we further performed experiments to demonstrate the direct integration of transient energy storage into microelectronic systems. To accomplish this, we used a commercially obtained integrated silicon microchip made with copper processing. To produce a fully integrated transient energy storage electrode, we etched porous silicon into the backside of the microchip, and coated the porous silicon with $19 \mathrm{~nm} \mathrm{VO}_{x}$ in a similar manner as described previously (Fig. 5A and B). This leads to a configuration where the energy stored in the backside of the microchip can power the front-side components, and operation of the total system can be systematically deactivated based on the transient energy storage material. To demonstrate transient behavior of the integrated electrode, it was exposed to identical triggering environments $(1 \mathrm{M} \mathrm{NaOH})$ and after 30 minutes, full dissolution of $\mathrm{VO}_{x}$ /porous silicon active material was observed. This demonstrates integration of transient energy storage with silicon electronics for the first time. In addition to fully transient systems, this also provides a route toward

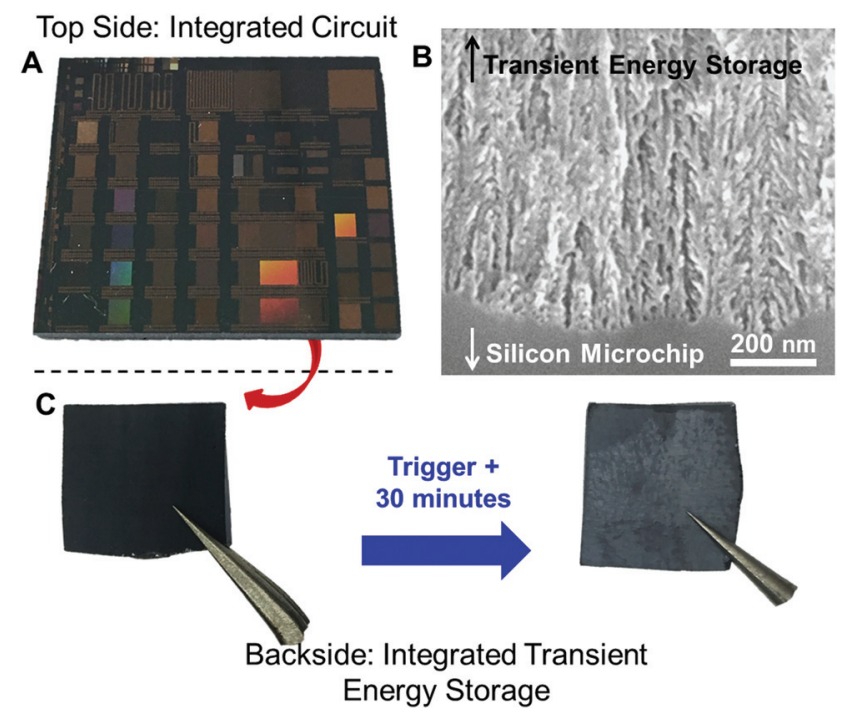

Fig. 5 Transient behavior of an integrated circuit microchip where the backside is directly etched and coated with $\mathrm{VO}_{x}$ to provide on-board integrated storage. (A) Front side image of the integrated circuit microchip, (B) SEM image showing the interface between the silicon material in the microchip and the on-board transient energy storage material, and $(C)$ image showing the backside of the microchip before and after triggering, where the transient energy storage material is visually fully dissolved. This opens a new class of transient electronics where onboard transient power sources that power integrated electronics can enable transient operation even when the electronic components themselves do not exhibit transience. integrated transient electronics where the electronic components by themselves may not be transient, but their electronic function can be disabled by the transient behavior of the integrated power source.

Overall, whereas we highlight this route for $\mathrm{VO}_{x}$ coated onto porous silicon, we emphasize that porous silicon is a universal template for transient energy storage. The ability to coat other metal oxides or nitrides that exhibit energy storage capability into the interior of transient porous silicon materials opens a full design space to engineer new transient systems for electronics, biomedical applications, or defense applications. This builds on the principle that any system that is designed to dissolve or disappear when triggered still requires a power source to facilitate operation prior to triggering - with the most elegant design being an integrated and fully transient power system. Here we demonstrate the first such integrated power source into silicon materials, with promise to diverse transient applications.

\section{Conclusions}

In summary, we demonstrate the first design for a transient energy storage electrode material that is integrated seamlessly into silicon material that can dually function for either transient or non-transient silicon-based electronics. By combining the native transient properties of porous silicon with the controlled gradient coatings of active materials using atomic layer deposition, our work highlights the capability to achieve stable energy storage $\left(>20 \mathrm{~F} \mathrm{~g}^{-1}\right)$ until a trigger is applied, which deactivates the energy storage function in a matter of seconds, with full dissolution occurring within 30 minutes. We demonstrate this specifically for vanadium oxide $\left(\mathrm{VO}_{x}\right)$ coated onto porous silicon, where the $\mathrm{VO}_{x}$ plays a role to protect the reactive porous silicon and provide active redox storage until a trigger is applied, which dissolves both the porous silicon and the $\mathrm{VO}_{x}$ materials. We further explicitly demonstrate the integration of transient energy storage using this approach into the backside of a silicon integrated circuit, emphasizing the simplicity in transitioning this approach to integrated applications. As silicon is a benchmark material for evolving efforts in transient electronics, this technique is generalizable to a wide range of different coatings that can be coupled with porous silicon using ALD for stable performance and triggered transience. In the circumstance that not all components in a circuit may be transient, the utility of a transient power source is that all on-board components being powered will ultimately be disabled in concert with the integrated power system - a feat that we show can be achieved in a matter of seconds using this design.

\section{Acknowledgements}

We gratefully acknowledge helpful discussions with Dr Sanjay Mathur and Ms Shuangzhou Wang regarding ALD processing, and Dr Huazhi Li and Dr Stephen Bachman at Arradiance for critical insight into $\mathrm{ALD} \mathrm{VO}_{x}$ process development. We also 
thank Adam P. Cohn, Landon Oakes, Andrew Westover, and Mengya Li for useful discussions regarding this work, and Dr Rizia Bardhan for the use of lab facilities and insights regarding material fabrication and characterization. This work was supported by National Science Foundation grant CMMI 1334269. A.D. and K.S. are supported in part by the National Science Foundation Graduate Research Fellowship under Grant No. 1445197.

\section{References}

1 S. W. Hwang, H. Tao, D. H. Kim, H. Y. Cheng, J. K. Song, E. Rill, M. A. Brenckle, B. Panilaitis, S. M. Won, Y. S. Kim, Y. M. Song, K. J. Yu, A. Ameen, R. Li, Y. W. Su, M. M. Yang, D. L. Kaplan, M. R. Zakin, M. J. Slepian, Y. G. Huang, F. G. Omenetto and J. A. Rogers, Science, 2012, 337, 16401644.

2 L. Yin, H. Y. Cheng, S. M. Mao, R. Haasch, Y. H. Liu, X. Xie, S. W. Hwang, H. Jain, S. K. Kang, Y. W. Su, R. Li, Y. G. Huang and J. A. Rogers, Adv. Funct. Mater., 2014, 24, 645-658.

3 X. Huang, Y. H. Liu, S. W. Hwang, S. K. Kang, D. Patnaik, J. F. Cortes and J. A. Rogers, Adv. Mater., 2014, 26, 7371-7377.

4 S. W. Hwang, X. Huang, J. H. Seo, J. K. Song, S. Kim, S. Hage-Ali, H. J. Chung, H. Tao, F. G. Omenetto, Z. Q. Ma and J. A. Rogers, Adv. Mater., 2013, 25, 3526-3531.

5 C. W. Park, S. K. Kang, H. L. Hernandez, J. A. Kaitz, D. S. Wie, J. Shin, O. P. Lee, N. R. Sottos, J. S. Moore and J. A. Rogers, Adv. Mater., 2015, 27, 3783-3788.

6 C. Dagdeviren, S. W. Hwang, Y. W. Su, S. Kim, H. Y. Cheng, O. Gur, R. Haney, F. G. Omenetto, Y. G. Huang and J. A. Rogers, Small, 2013, 9, 3398-3404.

7 D. Son, J. Lee, D. J. Lee, R. Ghaffari, S. Yun, S. J. Kim, J. E. Lee, H. R. Cho, S. Yoon, S. X. Yang, S. Lee, S. T. Qiao, D. S. Ling, S. Shin, J. K. Song, J. Kim, T. Kim, H. Lee, J. Kim, M. Soh, N. Lee, C. S. Hwang, S. Nam, N. S. Lu, T. Hyeon, S. H. Choi and D. H. Kim, ACS Nano, 2015, 9, 5937-5946.

8 S. W. Hwang, D. H. Kim, H. Tao, T. I. Kim, S. Kim, K. J. Yu, B. Panilaitis, J. W. Jeong, J. K. Song, F. G. Omenetto and J. A. Rogers, Adv. Funct. Mater., 2013, 23, 4087-4093.

9 L. Yin, X. Huang, H. X. Xu, Y. F. Zhang, J. Lam, J. J. Cheng and J. A. Rogers, Adv. Mater., 2014, 26, 3879-3884.

10 K. Fu, Z. Liu, Y. G. Yao, Z. Y. Wang, B. Zhao, W. Luo, J. Q. Dai, S. D. Lacey, L. H. Zhou, F. Shen, M. Kim, L. Swafford, L. Sengupta and L. B. Hu, Nano Lett., 2015, 15, 4664-4671.

11 A. S. Westover, D. Freudiger, Z. S. Gani, K. Share, L. Oakes, R. E. Carter and C. L. Pint, Nanoscale, 2015, 7, 98-103.

12 L. Oakes, A. Westover, J. W. Mares, S. Chatterjee, W. R. Erwin, R. Bardhan, S. M. Weiss and C. L. Pint, Sci. Rep., 2013, 3, 3020.

13 I. H. Son, J. H. Park, S. Kwon, S. Park, M. H. Rummeli, A. Bachmatiuk, H. J. Song, J. Ku, J. W. Choi, J. M. Choi, S. G. Doo and H. Chang, Nat. Commun., 2015, 6, 7393.
14 X. B. Meng, X. Q. Yang and X. L. Sun, Adv. Mater., 2012, 24, 3589-3615.

15 S. Chatterjee, R. Carter, L. Oakes, W. R. Erwin, R. Bardhan and C. L. Pint, J. Phys. Chem. C, 2014, 118, 10893-10902.

16 R. Carter, S. Chatterjee, E. Gordon, K. Share, W. R. Erwin, A. P. Cohn, R. Bardhan and C. L. Pint, Nanoscale, 2015, 7, 16755-16762.

17 J. C. Badot, S. Ribes, E. B. Yousfi, V. Vivier, J. P. PereiraRamos, N. Baffier and D. Lincot, Electrochem. Solid-State Lett., 2000, 3, 485-488.

18 S. Boukhalfa, K. Evanoff and G. Yushin, Energy Environ. Sci., 2012, 5, 6872-6879.

19 W. Dong, D. R. Rolison and B. Dunn, Electrochem. SolidState Lett., 2000, 3, 457-459.

20 W. Dong, J. Sakamoto and B. Dunn, J. Sol-Gel Sci. Technol., 2003, 26, 641-644.

21 C. M. Huang, C. C. Hu, K. H. Chang, J. M. Li and Y. F. Li, J. Electrochem. Soc., 2009, 156, A667-A671.

22 Z. J. Lao, K. Konstantinov, Y. Tournaire, S. H. Ng, G. X. Wang and H. K. Liu, J. Power Sources, 2006, 162, 1451-1454.

23 S. D. Perera, B. Patel, N. Nijem, K. Roodenko, O. Seitz, J. P. Ferraris, Y. J. Chabal and K. J. Balkus, Adv. Energy Mater., 2011, 1, 936-945.

24 D. Sun, C. W. Kwon, G. Baure, E. Richman, J. MacLean, B. Dunn and S. H. Tolbert, Adv. Energy Mater., 2004, 14, 1197-1204.

25 B. Wang, K. Konstantinov, D. Wexler, H. Liu and G. X. Wang, Electrochim. Acta, 2009, 54, 1420-1425.

26 L. Q. Mai, L. Xu, C. H. Han, X. Xu, Y. Z. Luo, S. Y. Zhao and Y. L. Zhao, Nano Lett., 2010, 10, 4750-4755.

27 X. C. Tian, X. Xu, L. He, Q. L. Wei, M. Y. Yan, L. Xu, Y. L. Zhao, C. C. Yang and L. Q. Mai, J. Power Sources, 2014, 255, 235-241.

28 I. E. Rauda, V. Augustyn, L. C. Saldarriaga-Lopez, X. Y. Chen, L. T. Schelhas, G. W. Rubloff, B. Dunn and S. H. Tolbert, Adv. Funct. Mater., 2014, 24, 6717-6728.

29 R. Baddour-Hadjean, V. Golabkan, J. P. Pereira-Ramos, A. Mantoux and D. Lincot, J. Raman Spectrosc., 2002, 33, 631-638.

30 K. Le Van, H. Groult, A. Mantoux, L. Perrigaud, F. Lantelme, R. Lindstrom, R. Badour-Hadjean, S. Zanna and D. Lincot, J. Power Sources, 2006, 160, 592-601.

31 M. G. Willinger, G. Neri, E. Rauwel, A. Bonavita, G. Micali and N. Pinna, Nano Lett., 2008, 8, 4201-4204.

32 Y. Liu, M. Clark, Q. Zhang, D. Yu, D. Liu, J. Liu and G. Cao, Adv. Energy Mater., 2011, 1, 194-202.

33 Y. Wang and G. Cao, Adv. Mater., 2008, 20, 2251-2269.

34 S. Boukhalfa, K. Evanoff and G. Yushin, Energy Environ. Sci., 2012, 5, 6872-6879.

35 T. Singh, S. Wang, N. Aslam, H. Zhang, S. Hoffmann-Eifert and S. Mathur, Chem. Vap. Deposition, 2014, 20, 291-297.

36 J. W. Elam, D. Routkevitch, P. P. Mardilovich and S. M. George, Chem. Mater., 2003, 15, 3507-3517.

37 V. Khomenko, E. Frackowiak and F. Beguin, Electrochim. Acta, 2005, 50, 2499-2506. 